\title{
Common Genes Contribute to Depressive Symptoms and Heart Rate Variability: The Twins Heart Study
}

\author{
Shaoyong Su,' Rachel Lampert, ${ }^{2}$ Forrester Lee, ${ }^{2}$ J. Douglas Bremner, ${ }^{3}$ Harold Snieder, ${ }^{4,5}$ Linda Jones,' \\ Nancy V. Murrah,' Jack Goldberg, ${ }^{6}$ and Viola Vaccarino ${ }^{1,7}$ \\ ' Department of Medicine, School of Medicine, Emory University, United States of America \\ ${ }^{2}$ Department of Internal Medicine, Division of Cardiovascular Medicine, Yale University School of Medicine, United States of America \\ ${ }^{3}$ Department of Psychiatry and Behavioral Sciences, School of Medicine, Emory University, United States of America \\ ${ }^{4}$ Department of Epidemiology, University Medical Center Groningen, University of Groningen, Groningen, the Netherlands \\ ${ }^{5}$ Department of Twin Research and Genetic Epidemiology, St Thomas' Campus, King's College, United Kingdom \\ ${ }^{6}$ Vietnam Era Twin Registry and the Department of Epidemiology, School of Public Health and Community Medicine, University of Washington, \\ United States of America \\ ${ }^{7}$ Department of Epidemiology, Rollins School of Public Health, Emory University, United States of America
}

$\mathrm{D}$ epression and reduced heart rate variability (HRV) are predictors of coronary artery disease (CAD), and highly correlated with each other. However, little is known to what extend this correlation can be explained by common genetic components. We examined 198 middle-aged male twins $(121$ monozygotic and 77 dizygotic) from the Vietnam Era Twin Registry. Current depressive symptoms were assessed using the Beck Depression Inventory-II and HRV was assessed on 24-hour electrocardiographic Holter recordings. Five frequency domain variables were used, including ultra low frequency (ULF), very low frequency (VLF), low frequency (LF), high frequency (HF) and total power (TPow). Structural equation modeling was used to estimate shared genetic effects for depressive symptoms and the HRV frequency domains. Both depressive symptoms $\left(h^{2}=.5\right)$ and all measurements of HRV showed high heritability $\left(h^{2}=.43-.63\right)$. A significant inverse correlation was found between depressive symptoms and all HRV indices except LF and HF, with the highest coefficient ( $r)$ for TPow $(r=-.24, P=.01)$ and ULF ( $r$ $=-.24, P=.01$ ). Bivariate genetic modeling revealed significant genetic correlations between depressive symptoms and TPow $\left(r_{\mathrm{A}}=-.21, P=.04\right)$, as well as $\operatorname{ULF}\left(r_{A}=-.23, P=.02\right)$. Of the total covariance between depressive symptoms and these two HRV indices, over $80 \%$ was due to the same genetic factors. In conclusion, depressive symptoms are associated with decreased HRV and this association is due, in large part, to a shared genetic effect. These results suggest that a common neurobiological dysfunction links depression and autonomic dysregulation.

Keywords: depressive symptoms, heart rate variability, twin study, common genes
Depression has been associated with increased risk of morbidity and mortality in patients with coronary artery disease (CAD; Lett et al., 2004). However, the pathophysiologic mechanisms linking depression and cardiovascular disease have not been fully understood. Dysregulation of the autonomic nervous system (ANS) has been proposed as a plausible explanation (Carney et al., 2005b), since disordered autonomic function with increased sympathetic tone has been found in patients with depression, as evidenced by elevated plasma and urinary catecholamine levels (Veith et al., 1994).

A commonly used method for assessing autonomic modulation of cardiac function is to measure heart rate variability (HRV), a noninvasive assessment of beat-to-beat heart rate fluctuations over time. Low HRV reflects excessive cardiac sympathetic or inadequate parasympathetic modulation (Pagani et al., 1986), and is a strong, independent predictor of mortality in patients with acute myocardial infarction (Bigger et al., 1992) as well as in general population (Dekker et al., 2000; Tsuji et al., 1996). Major depression and depressive symptoms are associated with decreased HRV, both in patients with CAD (Carney et al., 2001; Vigo et al., 2004) and in community subjects (Udupa et al., 2007; van der Kooy et al., 2006). However, the causal direction of this association remains unclear. Clinical studies have shown that HRV increases in depressed patients following pharmacological antidepressant treatment and cognitive-behavioral

Received 01 May, 2009; accepted 21 November, 2009.

Address for correspondence: Viola Vaccarino, MD, PhD, Emory University School of Medicine, Department of Medicine, Division of Cardiology, 1256 Briarcliff Road NE, Suite-1 North, Atlanta, GA 30306. E-mail: viola.vaccarino@emory.edu 


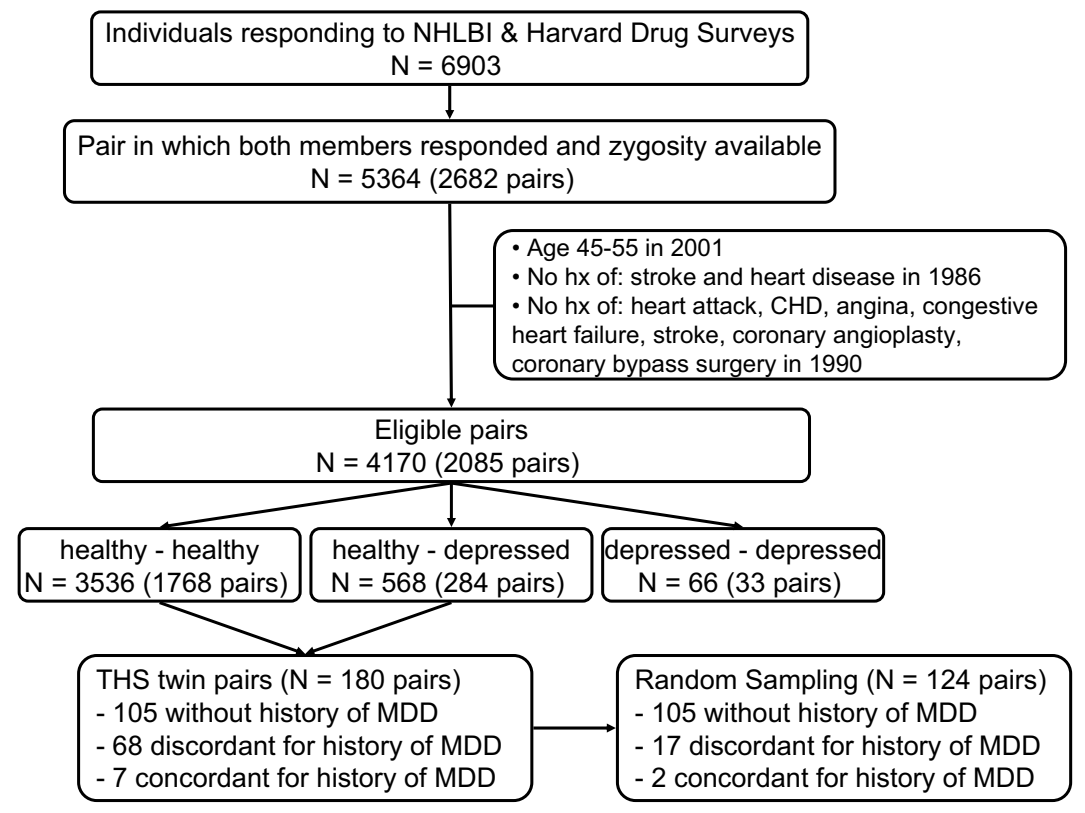

Figure 1

Flow chart showing the construction of the Twins Heart Study sample.

therapy (Khaykin et al., 1998). On the other hand, stimulation of the left cervical vagus nerve has been recently found to be useful in treating depression (Nemeroff et al., 2006). These results underscore the possible bidirectional association between depression and cardiac autonomic dysregulation.

An alternative explanation for the link between depression and HRV is that these two phenotypes share a common genetic substrate. Both depression and HRV are in large part under genetic control (Kupper et al., 2004; Levinson., 2006); therefore it is plausible that their association could result from shared genes, perhaps genes implicated in a common neurobiological pathway. Discovery of such common genetic substrate may point towards a common etiological pathway and improve our understanding of the mechanisms underlying neural-cardiac interactions. The purposes of the current study were to estimate the heritability of depressive symptoms and HRV indices in a sample of middle-aged male twins and to examine in detail the role of genetic influences on their correlation using structural equation modeling.

\section{Materials and Methods \\ Subjects}

The Twins Heart Study (THS) included 360 middleaged male twins from the Vietnam Era Twin (VET) Registry (Goldberg et al., 2002), who were all born between 1946 and 1956 (>90\% of the twins in the VET registry fall into this range). The methods of construction of this sample are shown in Figure 1 and were also described before (Su et al., 2008). Briefly, the twins were free of a self-reported previous diagnosis of cardiovascular disease based on survey data collected in 1990 (Scherrer et al., 2003), including a previous diagnosis of myocardial infarction, coronary heart disease, angina, congestive heart failure or stroke, or previous coronary angioplasty or coronary bypass surgery. From this group, we randomly sampled two groups of twin pairs: one group included twin pairs discordant for major depressive disorder (MDD), where one member of the pair had a lifetime history of MDD and the other did not; the second group of twins included pairs where neither had a history of MDD. As shown in Figure 1, the sampling design of THS, with over-representation of MDDdiscordant pairs and MDD-free pairs, could bias heritability estimation of depressive symptoms. In order to minimize such bias, we further randomly selected twin pairs from THS to approximate the MDD distribution in the VET Registry. Specifically, for the current study we included all the THS pairs without MDD history, and randomly selected 17 MDD-discordant twin pairs and 2 MDD-concordant twin pairs (Figure 1). This procedure yielded a sample for analysis with a MDD distribution similar to the original sample, i.e., 105 normal twin pairs (85\%), 17 MDD-discordant twin pairs (13\%) and 2 MDD-concordant twin pairs $(2 \%)$. After complete description of the study to the subjects, written informed consent was obtained. The study was approved by the Institutional Review Board of the Emory University School of Medicine.

\section{Assessment of Depressive Symptoms}

We administered the Beck Depression Inventory-II (BDI-II), a standardized scale providing a continuous measure of depressive symptoms (Beck et al., 1996). This self-report instrument has been used extensively in 
community samples and has satisfactory test-retest and internal consistency reliability (Osman et al., 2004).

\section{Measurement of Heart Rate Variability}

Twins wore an ambulatory ECG (Holter) monitor (GE Marquette SEER digital system) for 24 hours. Both twins in a pair were studied at the same time and their recording times, schedule and activity level during the recording were matched. All activity was restricted to quiet walking in the clinical facility or around the campus. Participants were instructed to refrain from smoking and drinking alcohol or coffee during the recording. HRV data were analyzed following published methodology (Bigger et al., 1992; Lampert et al., 2003). The power spectrum was integrated over four discrete frequency bands: ultra low frequency (ULF) < .0033 Hz; very low frequency (VLF) .0033 to $.04 \mathrm{~Hz}$; low frequency (LF) .04 to $.15 \mathrm{~Hz}$; high frequency (HF) .15 to $.40 \mathrm{~Hz}$, and total power (TPow) < $.40 \mathrm{~Hz}$. All HRV data were log-transformed for analysis. Twins with $>20 \%$ interpolation or $<18$ recorded hours were excluded from the analysis.

\section{Other Measurements}

A medical history and a physical exam were obtained from all twins. Weight and height were used to calculate body mass index (BMI). Physical activity was assessed by means of a modified version of the Baecke Questionnaire of Habitual Physical Activity used in the Atherosclerosis Risk in Communities Study (Richardson et al., 1995); this is a 16-question instrument documenting level of physical activity at work, during sports and non-sports activities. The global physical activity score was used in the analysis. Cigarette smoking was classified into current versus never or past smoker.

\section{Statistical Analysis}

In initial descriptive analyses we compared means and percents of study factors between MZ and DZ twins. Correlations between depressive symptoms, HRV indices and other covariates were assessed using Pearson correlations for continuous variables and Spearman correlations for categorical variables. A priori specified covariates were further adjusted, including age, BMI, physical activity, smoking status, beta-blocker medication and history of CAD. $P$ values were corrected for the correlation between co-twins using generalized estimating equations (GEE). These analyses were performed using the statistical software package SAS, Inc. version 9.0 (SAS, Inc., Cary, NC).

To estimate the relative contributions of genetic and environmental influences on the depressive symptoms and HRV indices, structural equation models were constructed using the software package $\mathrm{Mx}$ (Neale et al. 2003). The twin design allows separation of the observed phenotypic variance into underlying additive genetic variance (A), common environmental variance shared by a twin pair $(\mathrm{C})$, and environmental variance specific to individuals (E). The assumptions under these models were that MZ twins share $100 \%$ of their genes whereas DZ twins share $50 \%$ on average. Shared environmental effects were assumed to be $100 \%$ for both $\mathrm{MZ}$ and $\mathrm{DZ}$ twins since they were reared together, while unique environmental effects were not shared between the siblings for either MZ or DZ twins. A greater similarity of phenotype(s) in $\mathrm{MZ}$ twins as compared with $\mathrm{DZ}$ twins, as indicated by a higher correlation in $\mathrm{MZ}$ than $\mathrm{DZ}$ twins, suggests a genetic effect.

The univariate genetic models were fit to estimate the heritability for depressive symptoms and each HRV parameter. To examine the hypotheses that genetic and environmental factors contribute to the correlations of depressive symptoms and HRV, bivariate models fitting the association between these two traits were then examined. The phenotypic variation for each trait was decomposed into genetic variance (A), shared environmental variance $(\mathrm{C})$ and unshared (or unique) environmental variance (E) (Figure 2). The correlation between the two traits was similarly partitioned into components resulting from $\mathrm{A}, \mathrm{C}$ and $\mathrm{E}$ (Figure 2). Models were fit by the method of maximum likelihood. A series of nested submodels were each tested for their goodness of fit against a saturated model that placed no constraints on the elements of the estimated monozygotic and dizygotic twin variance/covariance matrices. The difference in likelihood values between a submodel and the full model is approximately distributed as $\chi^{2}$, with degrees of freedom (df) equal to the difference in $\mathrm{df}$ between the submodel and the full model. Akaike's Information Criterion (AIC) was also used to evaluate the relative fit of the various models. A lower AIC indicates a better balance between goodness of fit and parsimony. The $95 \%$ CIs around parameter estimates were examined to evaluate whether the genetic, shared environmental, or unique environmental contributions to depressive symptoms and HRV indices differed significantly from. Analyses were repeated after adjusting for covariates including age, BMI, physical activity, smoking status, betablocker medication and history of CAD.

\section{Results}

Of the 248 THS twins, 198 , including 80 pairs and 38 singletons (resulting from exclusion of the co-twin) had usable ambulatory ECG data (18 hours or more of recording with at least $80 \%$ noninterpolated intervals). The mean age $( \pm S D)$ was 55 years $( \pm 2.86)$, and age ranged from 47 to 60 years. None of the study factors showed a significant difference between MZ and DZ twins (Table 1).

Physical activity was significantly correlated with depressive symptoms and all HRV indices, except for HF. BMI was only significantly associated with LF. Current smokers had lower HRV and higher depressive symptom scores (Table 2). Depressive symptoms were significantly associated with decreased HRV indices including TPow $(r=-.24, P=.01)$, ULF $(r=$ $-.24, P=.01)$ and VLF $(r=-.19, P=.01)$, but not 


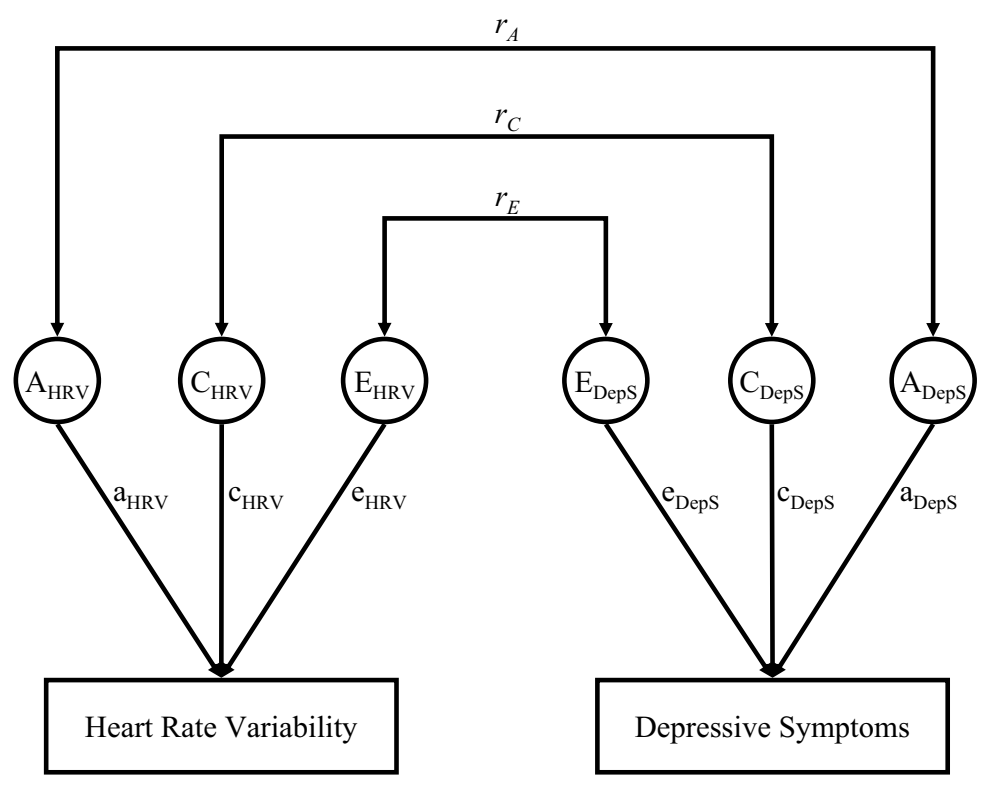

\section{Figure 2}

A schematic diagram for the bivariate biometric model examining the relationship between heart rate variability (HRV) and depressive symptoms (DepS). Factors influencing HRV and DepS include genetic factors (A), shared environment (C), and unique environment (E). Correlations between these factors across traits are represented as $r_{A}, r_{C}$ and $r_{E}$, respectively.

with LF ( $\mathrm{r}=-.12, P=.07)$ and $\operatorname{HF}(\mathrm{r}=-.08, P=.06)$. After adjusting for potential confounding factors including age, BMI, physical activity, smoking status, beta-blocker medication and history of CAD, the association between BDI and HRV was slightly attenuated but remained statistically significant for TPow $(P=$ $.02)$ and ULF $(P=.03)$. Thus, the subsequent bivariate genetic modeling focused on BDI, TPow and ULF.

For all HRV indices and depressive symptoms, the correlations in MZ twins were consistently higher than those in DZ twins, indicating genetic influence (Table 3). This was confirmed by univariate analysis.
The best-fitting models for all traits included only genetic and unique environmental contributions. Moderate to high heritability were estimated for all HRV indices (43-63\%). For depressive symptoms, the heritability was estimated at 50\% (95\% CI 26-68\%) and other variance was explained by the unique environmental factors. After adjusting for age, BMI, physical activity, smoking status, beta-blocker medication and history of CAD, the heritability estimations were slightly decreased but the overall results remained similar (data not shown). Further adjustment for antidepressant use did not change the results.

Table 1

Cardiovascular Risk Factors, Depressive Symptoms and Heart Rate Variability in Monozygotic (MZ) and Dizygotic (DZ) Twins

\begin{tabular}{|c|c|c|}
\hline & MZ twins $(n=121)$ & DZ twins $(n=77)$ \\
\hline Mean age, years & $54.3 \pm 2.9$ & $54.9 \pm 2.7$ \\
\hline Body mass index, $\mathrm{kg} / \mathrm{m}^{2}$ & $28.6 \pm 3.7$ & $3.0 \pm 5.0$ \\
\hline Physical activity (Baecke scores) & $7.49 \pm 1.5$ & $7.48 \pm 1.5$ \\
\hline Current smokers, \% & 18.2 & 15.6 \\
\hline History of coronary artery disease, $\%$ & 4.96 & 7.79 \\
\hline Taking beta-blocker medications, $\%$ & 7.44 & 3.90 \\
\hline Taking anti-depressant medications, \% & 11.6 & 1.4 \\
\hline Depressive symptoms (BDI scores) & $4.24 \pm 5.94$ & $4.90 \pm 7.06$ \\
\hline \multicolumn{3}{|l|}{ Index of heart rate variability } \\
\hline In Total Power, ms² & $9.45 \pm .47$ & $9.50 \pm .51$ \\
\hline In Ultra Low Frequency, ms² & $9.12 \pm .51$ & $9.20 \pm .54$ \\
\hline In Very Low Frequency, ms² & $7.65 \pm .52$ & $7.64 \pm .60$ \\
\hline In Low Frequency, ms² & $6.72 \pm .67$ & $6.68 \pm .73$ \\
\hline In High Frequency, ms² & $5.37 \pm .90$ & $5.41 \pm .92$ \\
\hline
\end{tabular}

Note: $S D$, standard deviation; In, logarithm transformation; BDI, beck depression inventory. 
Table 2

Phenotypic Correlations Between Covariates, Heart Rate Variability and Depressive Symptoms

\begin{tabular}{|c|c|c|c|c|c|c|}
\hline & In TPow & In ULF & In VLF & In LF & In HF & BDI scores \\
\hline Age & .07 & .07 & .14 & .02 & -.07 & -.19 \\
\hline Body mass index & -.06 & -.04 & -.06 & -.16 & -.04 & -.03 \\
\hline Physical activity & .20 & .16 & .27 & .19 & .09 & -.29 \\
\hline Current smoking & -.16 & -.17 & -.13 & -.12 & .03 & .25 \\
\hline History of CAD & -.08 & -.06 & -.12 & -.06 & -.11 & -.03 \\
\hline Beta-blocker medications & .02 & .02 & .02 & -.04 & .01 & .06 \\
\hline BDI scores & -.24 & -.24 & -.19 & -.12 & -.08 & - \\
\hline
\end{tabular}

Note: In, logarithm transformation; TPow, total power; ULF, ultra low frequency; VLF, very low frequency; LF, low frequency; HF, high frequency; CAD, coronary artery disease; $\mathrm{BDI}$, beck depression inventory

$P$ values are derived from generalized estimating equation models, and $<.05$ shown in bold.

Table 3

Correlations of MZ and DZ Twins and Univariate Model Fitting Results for Heart Rate Variability and Depressive Symptoms

\begin{tabular}{lcccc}
\hline & MZ & $\mathrm{DZ}$ & $\mathrm{a}^{2}(95 \% \mathrm{Cl})$ & $\mathrm{e}^{2}(95 \% \mathrm{CI})$ \\
\hline In TPow & .65 & .03 & $.63(.41-.77)$ & $.37(.23-.59)$ \\
In ULF & .59 & .09 & $.59(.37-.74)$ & $.41(.26-.63)$ \\
In VLF & .60 & .12 & $.57(.35-.73)$ & $.43(.27-.65)$ \\
In LF & .52 & .12 & $.43(.20-.61)$ & $.57(.39-.80)$ \\
In HF & .63 & .31 & $.56(.37-.70)$ & $.44(.30-.63)$ \\
BDI & .49 & .16 & $.50(.26-.68)$ & $.50(.32-.74)$
\end{tabular}

Note: In, logarithm transformation; TPow, total power; ULF, ultra low frequency; VLF, very low frequency; LF, low frequency; HF, high frequency; BDI, beck depression inventory $\mathrm{a}^{2}=$ additive genetic variance component (heritability), $\mathrm{e}^{2}=$ unique environmental variance component.

Bivariate model fitting for the relationship between depressive symptoms and HRV, including TPow and ULF, is shown in Table 4. For all models, the common environmental components $(\mathrm{C})$ could be dropped from the full model (ACE) without a significant reduction in fit $(P>.5)$. However, if the genetic components $(\mathrm{A})$ was dropped, the submodel was significantly worse than the ACE model $(P<.01)$. Thus, both before and after adjustment for covariates, the best fitting bivariate models for the relationship between depressive symptoms and HRV were the AE models.

As shown in Table 5, the parameter estimations for the best fitting $\mathrm{AE}$ models suggested that there were significant genetic correlations between TPow and BDI $\left(r_{A}=-.21,95 \mathrm{CI} \%,-.38\right.$ to -.02$)$, as well as ULF and BDI $\left(r_{A}=-.23,95 \mathrm{CI} \%,-.40\right.$ to -.04$)$. Of the overall covariance between depressive symptoms and TPow, about $80 \%$ was due to the same genetic factors. Similarly, for depressive symptoms and ULF, about $90 \%$ of the covariance was influenced by the same genetic factors. After adjustment for covariates, the genetic correlations between depressive symptoms and HRV indices remained statistically significant or at least borderline (Table 5).

\section{$\overline{\text { Discussion }}$}

In a sample of predominantly healthy twins we found that both depressive symptoms and HRV indices were highly heritable. The association between depressive symptoms and reduced HRV is due, in large part, to a shared genetic pathway, suggesting that a common neurobiological dysregulation links depression and autonomic dysfunction.

Reduced HRV is associated with depression or depressive symptoms, both in patients with CAD (Carney et al., 2001; Vigo et al., 2004), and in community subjects (Udupa et al., 2007; van der Kooy et al., 2006). Our findings are similar to previous studies in which associations between HRV and depression were stronger for lower frequency domains (Carney et al., 2001). In addition, the lower frequency bands ULF and VLF, which account for $90 \%$ of the total power in a 24-hour period, have been most strongly associated with mortality in post-myocardial infarction patients (Bigger et al., 1992; Carney et al., 2005a).

Although several distinct HRV frequency bands of the heart period power spectrum are commonly measured, the relative contributions of sympathetic and parasympathetic activity to these HRV indices cannot be precisely specified. ULF, VLF, and LF power are all influenced by both sympathetic and parasympathetic systems, whereas HF is largely thought to reflect parasympathetic modulation (Taylor et al., 1998). In addition, ULF and VLF may also be affected by daynight changes in heart period, especially when activity is controlled; these changes, in turn, may be influenced by autonomic activity (1996; Roach et al., 2004). 
Table 4

Goodness of Fit Statistics From the Bivariate Genetic Models for Heart Rate Variability and Depressive Symptoms, Before and After Adjustment for Covariates

\begin{tabular}{|c|c|c|c|c|c|c|c|}
\hline Traits & Model & $-2 \mathrm{LL}$ & $d f$ & $-2 \mathrm{LL}$ & $d f$ & $P$ value & AIC \\
\hline \multicolumn{8}{|l|}{ Unadjusted } \\
\hline \multirow[t]{4}{*}{ In TPow \& BDI } & Full model (ACE) & 1521.9 & 385 & & & & 751.8 \\
\hline & Drop all C (AE model) ${ }^{*}$ & 1521.9 & 388 & .00 & 3 & .99 & 745.8 \\
\hline & Drop all A (CE model) & 1535.1 & 388 & 13.3 & 3 & .004 & 759.1 \\
\hline & Drop all $A$ and $C$ (E model) & 1557.3 & 391 & 35.4 & 6 & $<.001$ & 755.3 \\
\hline \multirow[t]{4}{*}{ In ULF \& BDI } & Full model (ACE) & 1554.7 & 385 & & & & 784.7 \\
\hline & Drop all C (AE model) ${ }^{*}$ & 1554.7 & 388 & .00 & 3 & .99 & 778.7 \\
\hline & Drop all A (CE model) & 1566.4 & 388 & 11.7 & 3 & .009 & 79.4 \\
\hline & Drop all $A$ and $C$ (E model) & 1587.3 & 388 & 32.6 & 6 & $<.001$ & 805.3 \\
\hline \multicolumn{8}{|l|}{ Adjusted $^{\dagger}$} \\
\hline \multirow[t]{4}{*}{ In TPow \& BDI } & Full model (ACE) & 1463.9 & 381 & & & & 701.9 \\
\hline & Drop all C (AE model) ${ }^{*}$ & 1463.9 & 384 & .005 & 3 & .99 & 695.9 \\
\hline & Drop all A (CE model) & 1473.8 & 384 & 9.83 & 3 & .02 & 705.8 \\
\hline & Drop all $A$ and $C$ (E model) & 1495.0 & 387 & 31.0 & 6 & $<.001$ & 721.0 \\
\hline \multirow[t]{4}{*}{ In ULF \& BDI } & Full model (ACE) & 1496.5 & 381 & & & & 734.5 \\
\hline & Drop all C (AE model) ${ }^{*}$ & 1496.5 & 384 & .02 & 3 & .99 & 728.5 \\
\hline & Drop all A (CE model) & 1505.4 & 384 & 8.90 & 3 & .03 & 737.4 \\
\hline & Drop all $A$ and $C$ (E model) & 1525.4 & 387 & 28.9 & 6 & $<.001$ & 751.4 \\
\hline
\end{tabular}

Note: $-2 \mathrm{LL},-2$ times log-likelihood; $d f$, degree of freedom; , difference; AIC, Akaike's Information Criterion In, logarithm transformation; TPow, total power; ULF, ultra low frequency; BDI, beck depression inventory $A$, additive genetic component; $C$, shared environmental component; $E$, unique environmental component "The best-fitting model

tAdjusted for age, BMI, physical activity, smoking status, beta-blocker medication and history of CAD.

Unlike the current study, previous investigations have seldom controlled for physical activity. In our study, activity during the recording was matched between twins, and we also adjusted for habitual physical activity in the analysis.

Previous twin and family studies have shown an important role of genetic factors in the liability to depression and in the regulation of cardiac autonomic activity. Heritability is estimated to account for 37$75 \%$ of the liability for major depressive disorder. Depressive symptoms show a more modest but significant genetic influence (Kendler et al., 2006; Silberg et al., 1990; Su et al., 2008). Studies of HRV in families and twins suggest that a considerable part of the variation in these indices can be explained by genetic factors, with heritability estimations between .13 and .71 for a variety of HRV indices (Singh et al., 2001; Wang et al., 2005). Overall, the results of the present study are in agreement with these previous findings.

This is the first study to examine whether depression and disordered autonomic function share a common underlying mechanism, such as a common genetic vulnerability. By constructing bivariate genetic models in $\mathrm{MZ}$ and $\mathrm{DZ}$ twins, our study provided a unique opportunity to determine the extent to which the observed correlation between depression and HRV is caused by common genes. Both before and after adjusting for covariates, significant genetic correlations were observed between depressive symptoms and
TPow and ULF. Of the total genetic variation of depression and HRV indices, about $80-90 \%$ was due to the same genetic factors. These results indicate that common genes contribute substantially to the covariation of these two phenotypes.

Common genes that may be involved in regulation of both depression and autonomic function include those in the hypothalamus-pituitary-adrenal (HPA) axis, or in the sympathetic, parasympathetic and serotonin pathways, which have been related to depression and may be relevant for autonomic regulation (Belmaker \& Agam, 2008; Levinson, 2006). For example, hypothalamic corticotrophin-releasing hormone $(\mathrm{CRH})$ was found to be increased in medically healthy patients with depressive symptoms; it, in turn, leads to sympathetic activation with increased norepinephrine production and decreased HRV (Grippo \& Johnson 2002). Recent studies have observed a higher prevalence of certain alleles and haplotypes in the CRH receptor gene and glucocorticoid receptor gene in major depression patients than controls (Liu et al. 2006; van Rossum et al. 2006). In addition, genetic polymorphisms in serotonergic genes, such as serotonin transporter, serotonin receptors and monoamine oxidase $\mathrm{A}$, have been associated with depression (McCaffery et al., 2006). Although the relationship of these polymorphisms with autonomic dysfunction is not known, recent experimental studies in both human and animals have indicated that 
Table 5

Parameter Estimates from the Best Fitting Bivariate Models for Heart Rate Variability and Depressive Symptoms, Before and After Adjustment for Covariates

\begin{tabular}{llll}
\hline Traits & $\mathrm{a}^{2}(95 \% \mathrm{Cl})$ & $\mathrm{e}^{2}(95 \% \mathrm{Cl})$ & $r_{A}(95 \% \mathrm{Cl})$ \\
\hline $\begin{array}{l}\text { Unadjusted } \\
\text { In TPow }\end{array}$ & $0.64(.42-.77)$ & $0.36(.23-.58)$ & $-0.21(-.38--.02)$ \\
BDI & $0.52(.28-.69)$ & $0.48(.31-.72)$ & $-0.23(-.40--.04)$ \\
In ULF & $0.61(.39-.75)$ & $0.39(.25-.61)$ & $-0.05(-.20-.06)$ \\
BDI & $0.52(.28-.69)$ & $0.48(.31-.72)$ & $-0.02(-.17-.10)$ \\
Adjusted & & & $-0.19(-.36-.002)$ \\
In TPow & $0.62(.40-.76)$ & $0.38(.24-.60)$ & $-0.02(-.17-.11)$ \\
BDI & $0.45(.20-.63)$ & $0.55(.37-.80)$ & $-0.22(-.39--.04)$ \\
In ULF & $0.6(.38-.74)$ & $0.4(.26-.62)$ & $0.01(-.13-.14)$ \\
BDI & $0.46(.21-.64)$ & $0.54(.36-.79)$ & \\
\hline
\end{tabular}

Note: In, logarithm transformation; TPow, total power; ULF, ultra low frequency; BDI, beck depression inventory; Cl, confidence interval

$\mathrm{a}^{2}$, additive genetic variance component (heritability); $\mathrm{e}^{2}$, unique environmental variance component

$r_{A^{\prime}}$ genetic correlation; $r_{E^{\prime}}$ unique environmental correlation

* Adjusted for age, BMI, physical activity, smoking status, beta-blocker medication and history of CAD

impaired serotonergic function may affect the variability of heart rate (Hildreth et al., 2008).

There are several limitations to this study. First, our study is cross-sectional, thus limited in the ability to discern the temporal order between depression and HRV. However, based on our results, the covariation of these two phenotypes is due in large part to a common genetic precursor rather than being a causeeffect relationship. Second, our sample is derived from a twin registry of military veterans, where the members may be in some ways different from the general population of similarly aged American males. Third, our analyses included only male twins, thus one should be cautious to extend our results to females.

In conclusion, we found that both depressive symptoms and HRV indices are heritable and the association between them is due, in large part, to a shared genetic effect. These results suggest that a common neurobiological dysfunction links depression and autonomic dysregulation. Our data provide important insight into the mechanisms underlying neural-cardiac interactions and point to the importance of uncovering common genetic variants that may be implicated in both depression and HRV. These results have substantial implications for our understanding of the link between depression and autonomic dysfunction, suggesting that genetic susceptibility may play an important role.

\section{Acknowledgments}

The United States Department of Veterans Affairs has provided financial support for the development and maintenance of the Vietnam Era Twin (VET) Registry. Numerous organizations have provided invaluable assistance, including: VA Cooperative Study Program; Department of Defense; National Personnel Records Center, National Archives and Records Administration; the Internal Revenue Service; NIH; National Opinion
Research Center; National Research Council, National Academy of Sciences; the Institute for Survey Research, Temple University.

We gratefully acknowledge the continued cooperation and participation of the members of the Vietnam Era Twin Registry. Without their contribution this research would not have been possible.

This study was supported by K24HL077506, R01 HL68630 and R01 AG026255 from the National Institutes of Health; by the Emory University General Clinical Research Center MO1-RR00039 and by grant $0245115 \mathrm{~N}$ and $0725513 \mathrm{~B}$ from the American Heart Association.

The Holter scanning software was a gift from GE Medical.

\section{References}

Beck, A. T., Steer, R. A., Brown, G. K. (1996). BDI-II. Beck Depression Inventory: Second Edition. San Antonio, TX: Psychological Corporation

Belmaker, R. H., \& Agam, G. (2008). Major depressive disorder. New England Journal of Medicine, 358, 55-68.

Bigger, J. T., Jr., Fleiss, J. L., Steinman, R. C., Rolnitzky, L. M., Kleiger, R. E., \& Rottman, J. N. (1992). Frequency domain measures of heart period variability and mortality after myocardial infarction. Circulation, $85,164-171$.

Carney, R. M., Blumenthal, J. A., Freedland, K. E., Stein, P. K., Howells, W. B., Berkman, L. F., Watkins, L. L., Czajkowski, S. M., Hayano, J., Domitrovich, P. P., \& Jaffe, A. S. (2005a). Low heart rate variability and the effect of depression on post-myocardial infarction mortality. Archives of Internal Medicine, 165, 1486-1491.

Carney, R. M., Blumenthal, J. A., Stein, P. K., Watkins, L., Catellier, D., Berkman, L. F., Czajkowski, S. M., O’Connor, C., Stone, P. H., \& Freedland, K. E. (2001). 
Depression, heart rate variability, and acute myocardial infarction. Circulation, 104, 2024-2028.

Carney, R. M., Freedland, K. E., \& Veith, R. C. (2005b). Depression, the autonomic nervous system, and coronary heart disease. Psychosomatic medicine, 67 Suppl 1, S29-33.

Dekker, J. M., Crow, R. S., Folsom, A. R., Hannan, P. J., Liao, D., Swenne, C. A., \& Schouten, E. G. (2000). Low heart rate variability in a 2-minute rhythm strip predicts risk of coronary heart disease and mortality from several causes: The ARIC Study. Atherosclerosis Risk In Communities. Circulation, 102, 1239-1244.

Goldberg, J., Curran, B., Vitek, M. E., Henderson, W. G., \& Boyko, E. J. (2002). The Vietnam Era Twin Registry. Twin Research, 5, 476-481.

Grippo, A. J., \& Johnson, A. K. (2002). Biological mechanisms in the relationship between depression and heart disease. Neuroscience and Biobehavioral Reviews, 26, 941-962.

Hildreth, C. M., Padley, J. R., Pilowsky, P. M., \& Goodchild, A. K. (2008). Impaired serotonergic regulation of heart rate may underlie reduced baroreflex sensitivity in an animal model of depression. American Journal of Physiology. Heart and Circulatory Physiology, 294, H474-48.

Kendler, K. S., Gatz, M., Gardner, C. O., \& Pedersen, N. L. (2006). A Swedish national twin study of lifetime major depression. American Journal of Psychiatry, 163, 109-114.

Khaykin, Y., Dorian, P., Baker, B., Shapiro, C., Sandor, P., Mironov, D., Irvine, J., \& Newman, D. (1998). Autonomic correlates of antidepressant treatment using heart-rate variability analysis. Canadian Journal of Psychiatry, 43, 183-186.

Kupper, N. H., Willemsen, G., van den Berg, M., de Boer, D., Posthuma, D., Boomsma, D. I., \& de Geus, E. J. (2004). Heritability of ambulatory heart rate variability. Circulation, 110, 2792-2796.

Lampert, R., Ickovics, J. R., Viscoli, C. J., Horwitz, R. I., \& Lee, F. A. (2003). Effects of propranolol on recovery of heart rate variability following acute myocardial infarction and relation to outcome in the Beta-Blocker Heart Attack Trial. American Journal of Cardiology, 91, 137-142.

Lett, H. S., Blumenthal, J. A., Babyak, M. A., Sherwood, A., Strauman, T., Robins, C., \& Newman, M. F. (2004). Depression as a risk factor for coronary artery disease: Evidence, mechanisms, and treatment. Psychosomatic Medicine, 66, 305-315.

Levinson, D. F. (2006). The genetics of depression: a review. Biological Psychiatry, 60, 84-92.

Liu, Z., Zhu, F., Wang, G., Xiao, Z., Wang, H., Tang, J., Wang, X., Qiu, D., Liu, W., Cao, Z., \& Li, W. (2006). Association of corticotropin-releasing hormone receptor1 gene SNP and haplotype with major depression. Neuroscience Letters, 404, 358-362.
McCaffery, J. M., Frasure-Smith, N., Dube, M. P., Theroux, P., Rouleau, G. A., Duan, Q., \& Lesperance, F. (2006). Common genetic vulnerability to depressive symptoms and coronary artery disease: A review and development of candidate genes related to inflammation and serotonin. Psychosomatic Medicine, 68, 187-200.

Neale, M. C., Boker, S. M., Xie, G., \& Maes, H. H. (2003). Mx: Statistical modeling (6th ed.). Richmond: Virginia Commonwealth University Medical School

Nemeroff, C. B., Mayberg, H. S., Krahl, S. E., McNamara, J., Frazer, A., Henry, T. R., George, M. S., Charney, D. S., \& Brannan, S. K. (2006). VNS therapy in treatment-resistant depression: Clinical evidence and putative neurobiological mechanisms. Neuropsychopharmacology, 31, 1345-1355.

Osman, A., Kopper, B. A., Barrios, F., Gutierrez, P. M., \& Bagge, C. L. (2004). Reliability and validity of the Beck depression inventory - II with adolescent psychiatric inpatients. Psychological Assessment, 16, 120-132.

Pagani, M., Lombardi, F., Guzzetti, S., Rimoldi, O., Furlan, R., Pizzinelli, P., Sandrone, G., Malfatto, G., Dell'Orto, S., \& Piccaluga, E. (1986). Power spectral analysis of heart rate and arterial pressure variabilities as a marker of sympatho-vagal interaction in man and conscious dog. Circulation Research, 59, 178-193.

Richardson, M. T., Ainsworth, B. E., Wu, H. C., Jacobs, D. R., Jr., \& Leon, A. S. (1995). Ability of the Atherosclerosis Risk in Communities (ARIC)/Baecke Questionnaire to assess leisure-time physical activity. International Journal of Epidemiology, 24, 685-693.

Roach, D., Wilson, W., Ritchie, D., \& Sheldon, R. (2004). Dissection of long-range heart rate variability: controlled induction of prognostic measures by activity in the laboratory. Journal of the American College of Cardiology, 43, 2271-2277.

Scherrer, J. F., Xian, H., Bucholz, K. K., Eisen, S. A., Lyons, M. J., Goldberg, J., Tsuang, M., \& True, W. R. (2003). A twin study of depression symptoms, hypertension, and heart disease in middle-aged men. Psychosomatic Medicine, 65, 548-557.

Silberg, J. L., Heath, A. C., Kessler, R., Neale, M. C., Meyer, J. M., Eaves, L. J., \& Kendler, K. S. (1990). Genetic and environmental effects on self-reported depressive symptoms in a general population twin sample. Journal of Psychiatric Research, 24, 197-212.

Singh, J. P., Larson, M. G., O’Donnell, C. J., \& Levy, D. (2001). Genetic factors contribute to the variance in frequency domain measures of heart rate variability. Autonomic Neuroscience, 90, 122-126.

Su, S., Miller, A., Snieder, H., Bremner, J., Ritchie, J., Maisano, C., Jones, L., Murrah, N., Goldberg, J., \& Vaccarino, V. (2008). Common genetic contributions to depressive symptoms and inflammatory markers in middle-aged men: The Twins Heart Study. Psychosomatic Medicine, 71, 152-158. 
Task Force of the European Society of Cardiology and the North American Society of Pacing and Electrophysiology. (1996). Heart rate variability: standards of measurement, physiological interpretation and clinical use. Circulation, 93, 1043-1065.

Taylor, J. A., Carr, D. L., Myers, C. W., \& Eckberg, D. L. (1998). Mechanisms underlying very low-frequency RR-interval oscillations in humans. Circulation, 98, 547-555.

Tsuji, H., Larson, M. G., Venditti, F. J., Jr., Manders, E. S., Evans, J. C., Feldman, C. L., \& Levy, D. (1996). Impact of reduced heart rate variability on risk for cardiac events: The Framingham Heart Study. Circulation, 94, 2850-2855.

Udupa, K., Sathyaprabha, T. N., Thirthalli, J., Kishore, K. R., Lavekar, G. S., Raju, T. R., \& Gangadhar, B. N. (2007). Alteration of cardiac autonomic functions in patients with major depression: A study using heart rate variability measures. Journal of Affective Disorders, 100, 137-141.

van der Kooy, K. G., van Hout, H. P., van Marwijk, H. W., de Haan, M., Stehouwer, C. D., \& Beekman, A. T. (2006). Differences in heart rate variability between depressed and non-depressed elderly. International Journal of Geriatric Psychiatry, 21, 147-15. van Rossum, E. F., Binder, E. B., Majer, M., Koper, J. W., Ising, M., Modell, S., Salyakina, D., Lamberts, S. W., \& Holsboer, F. (2006). Polymorphisms of the glucocorticoid receptor gene and major depression. Biological Psychiatry, 59, 681-688.

Veith, R. C., Lewis, N., Linares, O. A., Barnes, R. F., Raskind, M. A., Villacres, E. C., Murburg, M. M., Ashleigh, E. A., Castillo, S., Peskind, E. R., Pascualy, M., \& Halter, J. B. (1994). Sympathetic nervous system activity in major depression. Basal and desipramineinduced alterations in plasma norepinephrine kinetics. Archives of General Psychiatry, 51, 411-422.

Vigo, D. E., Nicola Siri, L., Ladron De Guevara, M. S., Martinez-Martinez, J. A., Fahrer, R. D., Cardinali, D. P., Masoli, O., \& Guinjoan, S. M. (2004). Relation of depression to heart rate nonlinear dynamics in patients $\geq 60$ years of age with recent unstable angina pectoris or acute myocardial infarction. American Journal of Cardiology, 93, 756-76.

Wang, X., Thayer, J. F., Treiber, F., \& Snieder, H. (2005). Ethnic differences and heritability of heart rate variability in African- and European-American youth. American Journal of Cardiology, 96, 1166-1172. 